DOI 10.37882/2223-2982.2020.12-3.24

\title{
ИННОВАЦИОННЫЙ ПОТЕНЦИАЛ РОССИЙСКОЙ МОЛОДЁЖИ В УСЛОВИЯХ ЦИФРОВИЗАЦИИ СИСТЕМЫ ОБРАЗОВАНИЯ: ВЕДУЩИЕ ТРЕНДЫ И ПЕРСПЕКТИВЫ РАЗВИТИЯ
}

\section{THE INNOVATIVE POTENTIAL OF RUSSIAN YOUTH IN THE CONTEXT OF DIGITALIZATION OF THE EDUCATION SYSTEM: LEADING TRENDS AND DEVELOPMENT PROSPECTS \\ S. Chernykh \\ E. Susimenko \\ A. Kovalenko}

Summary: This article is devoted to the consideration of the specifics of the implementation of the innovative potential of Russian youth in the context of the digitalization of education and the dominance of screen culture, which is turning into a key factor in the socialization of the younger generation. The article notes the risks associated with the digitalization of the Russian education system and the virtualization of educational practices against the background of increasing clip consciousness. The prospects for the further development of educational practices are considered in their connection with the realization by young people of their own innovative potential against the background of a more intensive implementation of information technologies in the educational process. The article clarifies the differences between the concepts used in the meanings of «information» and «digital», and also explicates the concept of «virtuality» on a number of examples.

Keywords: innovative potential of youth, virtual socialization, information society, digitalization, screen culture, media, distance education, online education.

\section{Черных Сергей Сергеевич}

Д.ф.н., профессор, Южно-российского государственного политехнического университета (НПИ), имени М.И. Платова s.s.chernykh@mail.ru

Сусименко Елена Владимировна

д.ф.н., профессор, Южно-Российский государственный политехнический университет (НПИ)

имени М.И. Платова, г. Новочеркасск

lesusima@yandex.ru

Коваленко Ангелина Мизаевна

К.с.н., доцент, Южно-Российский государственный политехнический университет (НПИ) имени М.И.

Платова, г. Новочеркасск

gmu-npi@yandex.ru

Аннотация: Данная статья посвящена рассмотрению специфики реализации инновационного потенциала российской молодёжи в условиях цифровизации образования и доминирования экранной культуры, которая превращается в ключевой фактор социализации подрастающего поколения. В статье отмечаются риски, связанные с цифровизацией системы российского образовании и виртуализацией образовательных практик на фоне усиления клипового сознания. Рассматриваются перспективы дальнейшего развития образовательных практик в их связи с реализацией молодёжью собственного инновационного потенциала на фоне более интенсивного внедрения информационных технологий в учебный процесс. В статье проясняются различия между понятиями, употребляемыми в значениях «информационный» и «цифровой», а также на ряде примеров эксплицируется понятие «виртуальность».

Ключевые слова: инновационный потенциал молодёжи, виртуальная социализация, информационное общество, цифровизация, экранная культура, медийность, дистанционное образование, онлайн-образование.

\section{Введение}

$\mathrm{B}$ настоящее время процесс цифровизации затронул все сферы функционирования общества в его глобальном масштабе, в результате чего мы стали свидетелями трансформации большинства социальных институтов и самих взаимодействий между людьми, постоянно происходящих в повседневной жизни. В данной
Связи актуальными стали дискуссии о «цифровом государстве», «цифровом правительстве», «цифровой экономике», а также об образовании, которое в свою очередь на наших глазах подвергается «цифровизации». Для нас также вполне очевидно, что сама цифровизация отечественного образования, связанная в первую очередь с переходом большей части студентов на дистанционное (он-лайн) обучение, заметно ускорилась в связи с рас-

Статья выполнена в рамках реализации гранта Президента Российской Федерации для государственной поддержки ведущих научных школ Российской Федерации (НШ-2582.2020.6) на тему «Государственная политика в сфере высшего образования и развитие инновационного потенциала молодежи: экономические и неэкономические детерминанты и механизмы в условиях регионализации социального пространства и становления индустрии 4.0». 
пространением вируса COVID-19, который по сути дела выступил важным источником её легитимизации. Спустя уже почти полгода можно говорить о привыкании значительной части студентов и преподавателей к сложившейся ситуации, которая, однако, требует серьёзного продумывания и всестороннего анализа, исходя из данных междисциплинарного исследования, объединяющего в себе эвристические возможности философии, социологии, психологии, культурологии и ряда других гуманитарных дисциплин.

В сложившейся ситуации важно рассмотреть траектории развития современной российской молодёжи, способность реализовать данной социально-демографической группой собственный инновационный потенциал. Вместе с тем необходимо осознать, что инновационный потенциал студентов в большей степени может быть раскрыт при посредстве информационных сетей, в которых активно работает современное образование. При этом перед гуманитарными науками встаёт задача пристального изучения современной «экранной культуры» и прояснение степени её влияния на раскрытие молодёжью своего инновационного потенциала на фоне экспансии интерактивных практик взаимодействия между преподавателями и студентами. Ведь избыточность разнообразной информации, которую можно обнаружить в сети он-лайн, зачастую способствует ее поверхностному прочтению, что существенно затрудняет интериоризацию научного материала, приобретаемую традиционным способом, например, в результате постоянного чтения и конспектирования.

Таким образом, можно предположить, что в результате цифровизации системы российского образования происходят существенные изменения, связанные с трансформацией прежних и появлением новых каналов реализации молодёжью своего инновационного потенциала, совершающиеся с учётом преобразования глобального социально-экономического уклада. Поэтому необходимо выявить основные тренды и дальнейшие перспективы развития инновационного потенциала молодёжи в условиях цифровизации образовательных практик и других ведущих институтов социализации.

\section{Инновачионный потенциал российской молоАёжи и риски шифровизашии системы образования}

Инновационный потенциал российской молодёжи по-прежнему остаётся в фокусе изучения поколения, социализация которого происходит в эпоху дальнейшего развития информационного общества и становления в нашей стране «цифрового» образования. Ранее отечественным социологом В.И. Чупровым был предложен социально-воспроизводственный подход изучения молодёжи в качестве специфической социально-демографической группы населения страны и мира, которой присуща функция развития и воспроизводства накопленных идеальных и материальных ценностей (Чупров, Зубок, 2011). Сам процесс социального воспроизводства состоит из трёх компонентов: трансляции, инновации и непосредственного воспроизводства (прежних практик на новом уровне). Следовательно, молодёжь не просто копирует и транслирует полученные знания о социальном мире, но и постоянно вносит в них инновации, в результате чего происходит обновление общественных взаимоотношений и всего социума в целом. Молодежь, таким образом, продолжает выступать субъектом социальных инноваций в условиях пандемии COVID-19, притом, что представители данной группы оказываются более адаптированными к цифровой образовательной среде, причём, например, в недавнем прошлом студенты в целом оказались больше психологически и технически готовы к дистанционному обучению, чем их преподаватели.

Итак, инновации представляют собой актуальные новшества, которые либо уже включены в различные социальные практики, либо могут быть внедрены в общественную жизнь в ближайшем будущем. Согласно определению Вал. А. Лукова, «инновационный потенциал молодежи» должен пониматься исследователями как особого рода «готовность проектировать изменения в сфере мысли или деятельности, имеющие целью перемены действительных обстоятельств жизни людей - независимо от направленности, масштабов и последствий таких перемен» (Луков, 2011. С.12). Инновационный потенциал молодёжи, однако, не всегда может быть реализован в должной мере без поддержки со стороны социальных институтов. Одним из ведущих институтов, помогающих раскрытию инновационного потенциала молодежи, несомненно, выступает именно институт образования.

Информация становится важным предметом потребления и содержанием досуга молодёжи, но также важной составляющей материалов, необходимых для реализации образовательных программ, совершенствования личности. Правда для позитивной переработки такого огромного числа информации нужны и соответствующие интеллектуальные «мощности». В условиях информационного общества молодой человек при соответствующей акцентуации может получить доступ к такому разнообразному образовательному материалу, который ещё в недавнем прошлом считался интеллектуальной роскошью. Но, однако, не всякий студент способен самостоятельно разобраться с реальным качеством обнаруживаемых в сети материалов, что, несомненно, требует консультирования со стороны преподавателей. Речь, конечно же, идёт в первую очередь о «дополнительном» образовательном контенте, хотя для желающих реализовать свой инновационный потенциал студентов именно интерес к дополнительным материалам свидетельствует 
об установке на углубленное изучение предмета.

Массовое производство самых разнообразных фейков и появление «фабрик троллей» является неотъемлемой часть виртуального ландшафта. Таким образом, с распространением избыточного числа, причем далеко не всегда проверенной информации, возрастают риски её не всегда адекватного восприятия в молодёжной среде, что также приводит к разного рода девиациям. В согласии с рискологической концепцией молодёжи Ю.А. Зубок - «риск, будучи социально обусловленным, возникает (1) в связи с переходным состоянием молодости как фазы жизненного пути и реализуется в процессе инновационной деятельности молодых людей; (2) под влиянием нового этапа социокультурной эволюции изменений в процессе передачи социального опыта между поколениями; (3) в силу кардинальных изменений механизма социального взросления и как следствие увеличения продолжительности социальной транзиции. При этом риск признается сущностной характеристикой молодёжи не только на социально-групповом, но и на индивидуально-личностном уровне» (Луков, 2012. С.278). Следовательно, в зависимости от специфических условий социализации и нахождения в отличных культурных средах на пути реализации инновационного потенциала молодёжи можно обнаружить разнообразные риски, большинство их которых связаны с проблемами социализации представителей данной группы.

Если отсутствие или перебои информации способны породить у молодого человека депрессивное состояние, то подобного рода негативные психотические состояния могут быть результатом информационного пресыщения. «Информация играет важную роль в саморегуляции социальных взаимодействий. Обеспечивая усвоение индивидами и группами определенных знаний и представлений, она прямо, или косвенно формирует мотивационную сферу сознания и нацеливает, регулирует настроение. Воздействие, оказываемое цифровой средой на детей и молодежь, обсуждается в контексте амбивалентности их физических, психических, социокультурных влияний» (Зубок, Чупров, 2019. С.11). Негативные аспекты, связанные с избыточным потреблением информации, могут привести к реализации молодым человеком собственных индивидуалистических, но при этом экстремальных и экстремистских проектов.

Таким образом, инновации можно обнаружить в самых различных сферах общественной жизни, включая практики образования, досуга, поиска любви и даже политического протеста. Вполне очевидно, что большая часть подобных практик в последнее время подверглась значительной виртуализации, но при этом они также попали под более пристальное цифровое регулирование. Здесь справедливо будет раскрыть понятие виртуализации, под которым в основном понима- ется коммуникация (осуществляемая, как правило, посредством экрана), которая в большинстве случаев не может быть полностью актуализирована в реальности. Виртуализация в первую очередь описывает специфику эмоционального состояния человека, проявляющегося в сетевых взаимоотношениях между людьми. Например, такое понятие как «хейтер» употребляется именно по отношению к человеку, который пишет болезненные комментарии, или постоянно ставит дизлайки, но при этом его ненависть в отношении других пользователей и интернет-объектов, как правило, не выходит за пределы сети. В целом человеческие аффекты (желание, любовь, ненависть), проявляющиеся в виртуальной, среде носят в сравнении с реальностью довольно ослабленный характер.

Далеко не все молодёжные инновации общество способно принять и признать легитимными практиками, напротив многие из них могут быть идентифицированы как девиантные. В данной связи целый ряд институтов, включая образование, выступает в роли своеобразного фильтра, который абсорбирует те или иные изменения. «Инновационный потенциал молодёжи оказывается в этом случае подобным горному ландшафту: определенные виды инноваций, идущих от молодёжи, приветствуются, другие блокируются неформальными средствами, третьи пресекаются как девиации, на четвертые общество смотрит, применяя дифференцирующий принцип свое - чужое, т.е. приглядывается к таким потенциальным инновациям как прорывным или, напротив, губительным для общества» (Луков, 2012. С.351). Возвращаясь к образованию, важно отметить, что оно в значительной степени продолжает сохранять и свою дисциплинирующую функцию, которая, однако, в сложившихся обстоятельствах все больше принимает цифровой характер.

Находясь в процессе социализации, молодые люди могут не всегда адекватно оценивать окружающую их реальность, в том числе и виртуальную, что во многом связано с биопсихическими характеристиками данной социально-демографической группы. «Реализация притязаний молодежи связана с преодолением множества внешних и внутренних противоречий, при попытке разрешения которых проявляется экстремальность. Как одна из характеристик психического состояния, присущего молодежному возрасту, экстремальность отражает различные формы максимализма в сознании и крайности в поведении на групповом и индивидуальноличностном уровнях» (Зубок, Чупров, 2017. С.33). Склонность к экстремальности (в оценках и поступках) может быть аффектирована деструктивным интернет-контентом, что приводит к делинквентному поведению. Вместе с тем процесс цифровизации образования предполагает, что в привычной для молодёжи информационной среде появляется дополнительный агент контроля и воспитания. Именно поэтому всё большее число официальных 
образовательных учреждений запускает в сети-интернет собственные просветительские проекты.

Таким образом, изучая современное общество, важно указать на то, что мы сталкиваемся с интеграцией виртуальных практик с реальными формами коммуникации, а также констатируем синтез различных социальных медиа (например, блогов и телевидения). Пожалуй, мы уже имеем дело с молодым поколением, в значительной степени сформированным в условиях экранной и цифровой культуры. «Развитие глобальных коммуникаций сопровождается кардинальными изменениями образа жизни современного человека. Слияние реальной и виртуальной сред, стирание границ реальной и виртуальной форм коммуникации, диффузия образцов взаимодействий, зарождавшихся преимущественной в сетевых коммуникациях и их выход в офлайн, изменение способов организации повседневной жизни, формирование новых социальных компетенций и кристаллизация феномена цифрового поколения "digitalgeneration" - peзультат стремительных изменений в информационном секторе среды обитания» (Зубок, Чупров, 2019. С.11). В данной связи также наблюдается тенденция востребованности молодёжных трендов в среде представителей старших поколений, которые стремятся освоить или адаптировать под себя молодёжные практики. Так, например, анализ языка показывает, что представители старших поколений стали активно включать в свой словарь молодёжный сленг. В целом можно говорить о том, что информационные сети и длительное нахождение в виртуальной среде интернета существенно сближают позиции различных поколений по целому ряду дискуссионных вопросов.

На реализацию инновационного потенциала российской молодёжи в контексте цифровизации, кроме всего прочего, влияет способность многих молодых людей действовать трансгрессивным образом. Большая часть молодёжи устремлена в будущее, по крайней мере, люди этого возраста склонны мыслить, что самое лучшее ещё впереди. Поэтому молодые люди как бы спешат оказаться в будущем, пытаясь преодолеть рутину настоящего, и здесь обнаруживаются дополнительные риски, связанные например с делинквентным употреблением психотропных веществ. «В изменяющейся социальной реальности особую роль приобретает трансгрессивность, отражающая способность молодых людей к символическому преодолению виртуальных границ социального времени и пространства» (Зубок, Чупров, 2017. С.34). Данная способность, присущая, как полагают исследователи, рассматриваемой группе скорее все-таки выполняет функцию механизма социальной защиты, срабатывающего в условиях неопределенности. «Основанная на интуитивном предвидении вектора возможных изменений, она позволяет молодому человеку оптимизировать свои ресурсы в настоящем и развивать необходимые компетенции, ориентируясь на образцы незримого, интуитивно ощущаемого будущего» (Зубок, Чупров, 2017. Там же). Реализация инновационного потенциала связана не только с трансгрессивностью и экстремальностью сознания молодёжи, но и с образовательной «цифровой» средой, которая в настоящее время значительно расширилась и постепенно включает в орбиту своего влияния досуговые практики. По крайней мере, для небольшой группы молодых интеллектуалов открыты возможности культурного роста, досуга и коммуникации с подобными себе людьми практически по всему миру, или как минимум в масштабе целой страны.

При этом риски цифровизации системы российского образования рассматриваются, как правило, сквозь призму острого дефицита живого общения между преподавателями и студентами, который достиг одного из своих пиков в период эпидемии COVID-19 в конце 2020 и начале 2021 годов. В данной связи можно констатировать, что особенно между преподавателями и студентами второго и третьего курса возникла существенная коммуникативная дистанция, в результате чего последние могут не дополучить соответствующих личностно-направленных консультаций и рекомендаций, способных оказать влияние на дальнейшие траектории их развития. В результате существенно снизилось влияние преподавателей на самоопределение студентов в рамках дальнейшего выбора дисциплин и последующей научной ориентации.

\section{Инновационный потеншиал российской мо^одёжки в контексте Аоминирования экранной культуры и виртуализашии образовательных практик}

Основные изменения современной культуре происходят по линии её цифровизации, где её ещё большая репрезентативность, медийность и визуальность продуктов культур-индустрии достигается посредством присутствия в сети-интернет. Это касается научных или околонаучных дискуссий, которые становятся доступными огромному числу пользователей. «В целом, информационно-цифровое пространство новой реальности становится площадкой конструирования новых смыслов и представлений, формирующих особый тип культуры» (Зубок, Чупров, 2019. С.11). На этом фоне также наблюдается избыток образовательной информации, наличие в свободном доступе значительного числа лекций, выступлений, презентаций и других учебных материалов, преподавателей из разных российских и зарубежных университетов.

В настоящее время всё большее значение для молодёжи приобретает экранная культура, при этом, как бы следуя мировой тенденции, цифровое образование также стремится стать «гармоничным» сегментом «нового» типа визуальной культуры. В данной связи можно заметить как электронные презентации учебных курсов 
начинают доминировать над традиционными аудиоцентричными формами подачи материала. В результате у многих студентов даже на исторических примерах формируется клиповое сознание, что приводит к изменению работы собственного воображения. Современный российский философ Ф.И. Гиренок отмечает, что понятием "clipping" обозначают «всего лишь подборку газетных вырезок на определенную тему. Клип прост, как натюрморт. Это лоскут, часть, не отсылающая к целому. И одновременно клип требует грёз, фантазий, которыми заполняется место отсутствующего целого» (Гиренок, 2016. С.7). Наиболее распространенным типом креативности и реализации инновационного потенциала молодёжи становятся навыки фрагментации и склеивания композиций из самых разнообразных культурных объектов, что можно в полной мере обнаружить в блогосфере. Вместе с тем, стирается различие между аутентичным творчеством в его классическом понимании, которое также требует проработки разнообразного материала, и производством эклектичных клипов (культурных «нарезок»), в самом широком смысле.

В мире, где господствуют информационные технологии и массовое сознание, а сознание носит преимущественно клиповый характер, социальные взаимодействия приобретают качества большей ликвидности, текучести и ситуативности. «В условиях, когда все более значимым становится сетевой строй социальных взаимодействий, характерный для информационного общества, поведение человека все более отрывается от традиций и зависит от текущей ситуации. И если рассматривать традицию как каменную границу, воздвигнутую прошлым вокруг настоящего, то чтобы проникнуть в будущее, человек должен перешагнуть ее» (Луков, 2013. С.203). В целом люди и особенно молодёжь оказываются способными к быстрой смене различных идентичностей, таким образом, они оказываются приспособленными к социальным становлениям различного рода, в результате они довольно легко могут воспринять инновационные стили жизни.

В условиях роста угроз COVID-19 происходит захват «неэкранных» видов и жанров культуры собственно экранной индустрией, которые пронизывают собой интеракции современного человека таким образом, что ему всё труднее остаться наедине с собой без гаджета и монитора. При этом образование и досуг молодого человека в большей степени оказываются в диффузном состоянии. Повсеместно просветительские походы в музеи и на выставки заменятся своими виртуальными аналогами. «Благодаря YouTube, Instagram, Facebook, другим сетям общественная и обыденная жизнь как публичных медийных персонажей, так и любого пользователя предстает частью всеобщего экранного аттракциона. Работа, отдых, образование, личная жизнь реализуются в одном формате и позе сидения перед экраном. Речь идет о тотальном переформатировании всего образа жизни, его остранении, почти буквально эстетизации, хотя, вроде бы, психоэмоциональные проявления те же: смех, гнев, страх, гордость, ликование, стыд, печаль, скорбь, но они не просто переживаются от первого лица, будучи недоступными кому-то другому, они выражаются, фиксируются и презентируются часто в неотрефлектированном виде. Более того, благодаря цифровым технологиям, они превращаются в "данные"» (Тульчинский, 2020, С.33). В сложившейся ситуации образование также приобретает явный экранный характер, в результате чего происходит существенная «профанация» традиционного образовательного пространства, а аудиторные занятия с их прежней атмосферой приобретают характер экзотики и элитарности.

Однако тотальная эстетизация повседневной жизни, достигаемая посредством виртуальных практик, приводит к потере навыков рефлексивности, критического отношения и дистанции в отношении навязчивых визуальных образов. Вместе с тем, высокая скорость получаемой информации (потока образов), то есть презентируемых данных, не всегда доступных мозгу, просто не оставляет времени субъекту на их обработку и вдумчивое осмысление. «С такими тенденциями эстетизация утрачивает предметность и становится гиперреалистичной одновременно. Означающие презентаций не нуждаются в означаемых. Собственно, презентируются только данные. Точнее - их перманентный изменчивый поток. От пользователя (зрителя, слушателя, читателя) требуются не какие-то рассуждения, аргументация, наррация, оценки, а реакции на ситуацию. При этом эмоциональное отношение, его переживание редуцируется к непосредственной, желательно быстрой (автоматической) реакции. Новая животность как раз и заключается в том, что быстротечная череда таких реакций не оставляет места для памяти - эвфемизма сознания» (Тульчинский, 2020, С.36-37). Поэтому на фоне доминирования экранной (по сути, гиперэкранной) культуры образовательные практики должны с одной стороны неминуемо следовать общим тенденциям, но с другой стороны попытаться представить качественно иной информационный продукт, требующий как минимум остановки сознания и дальнейшего осмысления, в соответствии с той или иной научной парадигмой.

Таким образом, в задачи современного образования входит коррекция молодёжных инноваций, осуществляемых в виртуальном пространстве, а также их критическое осмысление, которое предполагает мониторинг наиболее актуальных сетевых трендов. Вместе с тем, процесс виртуализации самого образовательного контента ведущих ВУЗов, перевод многих ресурсов в формат экранной культуры может пониматься и как тенденция эгалитаризации современного образования, его большей доступности для всех желающих. 


\section{Зак^ючение}

В период пандемии коронавируса, то есть в условиях самоизоляции, цифровая (как впрочем и виртуальная) среда приобрела ещё более важную роль в конструировании социальных отношений и способах реализации творческого потенциала. Важно, однако, отметить, что под процессом цифровизации мы понимаем повсеместное внедрение электронных технологий, позволяющих создавать всеохватывающие базы данных, а применительно к образованию практически полностью перевести его в дистанционный режим, осуществляемый при посредстве глобальной сети-интернет с использованием соответствующих ресурсов, преимущественно с привлечением иностранного программного обеспечения. Вместе с тем прилагательное «цифровой/цифровая» в русском языке (как впрочем, и в мировом «англосферическом» контексте) по набору своих коннотаций совпадает с понятием «информационный/информационная» лишь частично, но в отличие от последнего в нём на первое место выступают значения, связанные с термином «контроль». Поэтому, когда речь заходит о цифровизации системы российского образования, мы в первую очередь сталкиваемся с введением новых правил зачетов и экзаменов, то есть с созданием дисциплинарных условий деперсонализированного и автоматизированного контроля знаний студентов, совершаемого на расстоянии. Можно сказать, что сам процесс цифровизации воспринимается как своего рода сетка, накладываемая на информационное поле в целях его институционального контроля и дальнейших ограничений.

Одной из важных задач по овладению научной культурой можно считать способность молодых людей к написанию самостоятельных текстов, рефератов, эссе и сочинений. Сейчас, однако, в условиях существенной виртуализации образовательных практик и доминирования экранной культуры мы сталкиваемся с тем, что, прежде всего студенты, приобретающие техническое образование, так и не овладевают в полной или хотя бы достаточной мере способностью излагать мысли на письме. Значительная часть материалов для подготовки докладов и научных сообщений главным образом скачивается из сети-интернет, причем зачастую без каких-либо вразумительных ссылок на первоисточники. В данной связи можно конечно говорить о кризисе в первую очередь гуманитарного образования в России и мире, чему способствует экспансия информационного общества, но с другой стороны можно сделать вывод о более интенсивном разделении труда, которое продолжает усиливаться в современную («цифровую») эпоху.

\section{ЛИТЕРАТУРА}

1. Гиренок Ф.И. Клиповое сознание. М.: Проспект, 2016.256 с.

2. Зубок Ю.А., Чупров В.И. Жизнедеятельность молодёжи в культурном пространстве изменяющейся реальности: теоретические подходы к исследованию // В сборнике: Культурное пространство молодежи: смыслы и практики. Материалы Всероссийской научно-практической конференции. Под общей редакцией Т.К. Ростовской. 2019. С. 9-18.

3. Зубок Ю.А., Чупров В.И. Современная социология молодёжи: изменяющаяся реальность и новые теоретические подходы // Россия реформирующаяся. 2017. № 15. С. 12-48.

4. Луков Вал. А. Биосоциология молодежи: теоретико-методологические основания: науч. монография. М.: Изд-во Моск. гуманит. ун-та, 2013.430 c.

5. Луков Вал. А. Инновационный потенциал: можно ли его считать атрибутом молодёжи // В сборнике: Государственная молодежная политика: российская и мировая практика реализации в обществе инновационного потенциала новых поколений. Материалы семинара для молодых ученых. Под общей редакцией Вал. А. Лукова; Московский гуманитарный университет, Институт фундаментальных и прикладных исследований. Москва, 2011. С. 7-16.

6. Луков Вал. А. Теории молодёжи: Междисциплинарный анализ. М.:Изд-во «Канон+», 2012. 656с.

7. Тульчинский Г.Л. Эстетика [не]исчезающих переживаний: глубокая семиотика современных экранных аттракционов // Наука телевидения. 2020. T.16. №2. C.23-41.

8. Чупров В.И., Зубок Ю.А. Социология молодёжи. М.: Норма, 2011. 336 с.

( Черных Сергей Сергеевич (s.s.chernykh@mail.ru), Сусименко Елена Владимировна (lesusima@yandex.ru), Коваленко Ангелина Мизаевна (gmu-npi@yandex.ru).

Журнал «Современная наука: актуальные проблемы теории и практики» 